\title{
EFFECTS OF STRUCTURAL COMPLEXITY AND CHEMICAL DEFENSES ON CRUSTACEAN ASSEMBLAGES ASSOCIATED WITH TWO MACROALGAE FROM PERNAMBUCO COAST
}

\author{
Alves, R.V.A. ${ }^{1,}$; Craveiro, N.J.A. ${ }^{1}$; Correia, F.R. ${ }^{1}$; Rebouças, P.H.L. ${ }^{1}$; Nascimento, M.S. ${ }^{2}$ \& Filho, J.S.R ${ }^{1}$ \\ ${ }^{1}$ Universidade Federal de Pernambuco (UFPE), Campus Recife, Laboratório de Bentos. \\ ${ }^{2}$ Universidade Federal de Pernambuco (UFPE), Campus Recife. Laboratório de Química de Produtos Naturais.
}

*Corresponding author: rodrigovnicius@gmail.com

\begin{abstract}
Marine macrophytes are known to provide protection against biotic and abiotic stressors, food and microhabitats for many invertebrates living on their surface. The composition of phytal communities can be related to a myriad of factors, both extrinsic (e.g. wave exposure, depth, turbidity), and intrinsic (e.g. algal chemistry, shape and structural complexity). Among the epifaunal groups, small crustaceans are one of the most abundant and diverse. Here, we analyzed both physical and chemical features of two intertidal seaweed species, Ulva fasciata and Gracilaria caudata, from Pernambuco coast, and their influence on associated crustacean communities. We collected five samples of both algae at Enseada dos Corais' sandreef. For each macroalgae, four samples were used for characterization of crustaceans and one for phytochemical tests for algal secondary metabolites. Algal structural complexity was expressed as fractal dimension ( $\mathrm{Da}$ - area fractal dimension and $\mathrm{Dp}$ - perimeter fractal dimension) and was determined using pictures of individual fronds on high and low magnification using ImageJ software. U. fasciata hosted more individuals $(n=54)$ than G. caudata $(n=18)$. In contrast, U. fasciata had a less diverse and more dominated community $\left(\mathrm{S}=3 ; \mathrm{J}^{\prime}=0.2275 ; \mathrm{H}^{\prime}=0.2499\right)$ compared to $\mathrm{G}$. caudata $(\mathrm{S}$ $=5 ; \mathrm{J}^{\prime}=0.8686 ; \mathrm{H}^{\prime}=1.398$ ). G. caudata had four types of secondary metabolites (terpenes, steroids, saponins and quinones), whereas U. fasciata only had quinones. The individual effects of the secondary metabolites on the epifaunal groups' preferences could not be evaluated, although it is possible that $U$. fasciata's relative low diversity of chemical defenses can be related to the high dominance of Elasmopus sp., wich has a known feeding preference for green algae. Both seaweeds were almost equally complex. Ulva fasciata had a higher Da mean value (1.924) comparing to G. caudata (1.800), on both magnifications. G. caudata had more complex borders $(\mathrm{Dp}=1.722)$ than $U$. fasciata $(\mathrm{Dp}=1.675)$, although we observed the inverse at higher magnification. Despite the similarity of their " $\mathrm{D}$ " values, both algae have considerably different chemical and morphofunctional traits that can provide distinct habitats and influence the epifauna's preferences.
\end{abstract}

Keywords: seaweed, benthos, phytal, secondary metabolites, fractal. 